\title{
PHYSICAL PARAMETERS, TENSILE AND COMPRESSIVE STRENGTH OF DOLOMITE ROCK SAMPLES: INFLUENCE OF GRAIN SIZE
}

\author{
Ali LAKIROUHANI ${ }^{\circledR 1}$, Farhad ASEMI ${ }^{\circledR 1}$, Afshin ZOHDI ${ }^{\circledR 2}$, \\ Jurgis MEDZVIECKAS ${ }^{3 *}$, Romualdas KLIUKAS ${ }^{3} 4$ \\ ${ }^{1}$ Department of Civil Engineering, Faculty of Engineering, University of Zanjan, Zanjan, Iran \\ ${ }^{2}$ Department of Geology, University of Zanjan, Zanjan, Iran \\ ${ }^{3}$ Department of Reinforced Concrete Structures and Geotechnics, Vilnius Gediminas Technical University, \\ Sauletekio al. 11, 10223 Vilnius, Lithuania \\ ${ }^{4}$ Department of Applied Mechanics, Vilnius Gediminas Technical University, Sauletekio al. 11, \\ 10223 Vilnius, Lithuania
}

Received 29 July 2020; accepted 19 October 2020

\begin{abstract}
The purpose of this paper is to investigate the strength, physical and engineering index parameters of selected dolomitic rocks with emphasis on grain size. For this purpose, three groups of dolomite from north western Iran, with the same mineral composition but different grain size, were selected; fine grain, medium grain and coarse grain. Three sets of laboratory experiments are performed on 32 samples: first; petrography tests for determining mineral composition and their percentage, and microstructure of rock containing grain size and grain size distribution, second; experiments to determine the physical properties of the rocks included density, compressional and shear wave velocity, and the third category of experiments included uniaxial compressive strength test, Brazilian tensile strength and point load strength. According to the results; there are significant positive correlation between grain size and uniaxial compressive strength $(r=0.89)$, point load strength $(r=0.58)$, Brazilian strength $(r=0.69)$, and average Young's modulus $(r=0.64)$. Also, with increasing grain size, density decreases $(r=-0.77)$. There is strong correlation between compressional wave velocity and shear velocity $(r=0.88)$. There are also a strong correlation among the uniaxial compressive strength, Brazilian tensile strength and point load strength.
\end{abstract}

Keywords: rock sample, laboratory tests, simple linear regression, dolomite rock, grain size, petrography, uniaxial compressive strength, compressional wave velocity, shear wave velocity, Brazilian tensile strength.

\section{Introduction}

Micro texture, mineralogical composition, petrographic and microstructural of rocks effect on their mechanical, physical and engineering index properties. Microstructure characteristics are related to the grain size, grain shape, and distribution in the matrix, porosity, interlocking, mineralogical composition, quartz content, and etc. So far many laboratory studies have been done for finding the relationship between microstructures of rock and macro scale features (Olsson, 1974; Eberhardt et al., 1999; Palchik \& Hatzor, 2004; Tandon \& Gupta, 2013; Amann et al., 2014; Ghazvinian et al., 2015; Ündül et al., 2015; Ündül, 2016; Farrokhrouz \& Asef, 2017; Festa et al., 2018; Garia et al., 2019; Aladejare, 2020; Hemmati et al., 2020), as well as numerical simulation by discrete element method (Lan et al., 2010; Nicksiar \& Martin, 2014; Tan et al., 2016), however, many of the results are not conclusive.

Grain size is a significant microstructure parameter that affects the mechanical behavior and physical properties of rock. Grain size is the most fundamental property of sedimentary rocks, affecting their transportation and deposition (Blott \& Pye, 2001). Many researchers have investigated effect of grain size on the mechanical properties of rocks. However, the correlation between grain size and strength parameters are mainly based on the investigation about granitic rocks, but the results are different and are divided into several categories.

At first, most experiments have shown that with increasing grain size, the sample strength decreases, for

*Corresponding author. E-mail: jurgis.medzvieckas@vgtu.lt 
instance, experimental results reported by Wong et al. (1996), Hugman and Friedman (1979), Fredrich et al. (1990), Hatzor and Palchik (1998), Palchik and Hatzor (2000), all indicated that rock strength parameters decrease with increasing grain size. Also Skinner (1959), Olsson (1974) and Přikryl (2001) for tests on anhydrite, dolomite and granite rocks reported decreased uniaxial compressive strength with increasing grain size. In these cases, Griffith's theory of elliptical cracks is used to interpret this result. According to this theory, the second root of the crack length inversely is proportional to the compressive stress. So if in this theory assume compressive stress equivalent to peak stress in the uniaxial compressive strength test, and assume crack length equal to the grain size, Then, by increasing the second root inverse of grain size, the peak strength decreases. Even in some of the above studies, an empirical relation similar to that of the Griffith's theory was presented. But Eberhardt et al. (1999) by experimental study of granite rocks, offered another reason for decreasing strength with increasing grain size; they conclude that the rock strength decreases with increasing grain size, but not because of crack initiation at lower stresses, but because of the process where crack propagation occurs along weakly available planes.

Alongside, these studies, tests by Sousa (2013) found a tendency for an increase of UCS proportional to quartz size, while for granite rock there was no relationship between UCS and grain size.

Ajalloeian et al. (2017) evaluated the effect of grain size on carbonate rocks and represented that uniaxial compressive strength had an increasing trend with increasing grain size for 0 to $5 \mathrm{~mm}$; and in the following it had a decreasing trend with increasing grain size for 5 to $50 \mathrm{~mm}$, in fact, carbonate rock with medium grain size had the highest uniaxial compressive strength. They also observed a similar trend for Young's modulus and wave velocity. The interval change of grain size in their study was between 0 and $50 \mathrm{~mm}$.

Meng and Pan (2007) assessed the relationship between petrographic characteristics and mechanical properties of sandstone and reported that uniaxial compressive strength of rock increased with increasing average size of bigger grain. The interval of grain size in their study varied between 0.1 to $0.3 \mathrm{~mm}$.

As can be seen, different results have been observed on the effect of particle size on strength parameters in previous studies. One reason is that, grain size is not the only microstructural parameter that affects rock strength, unless the samples are homogeneous enough that the only effective parameter in their strength to be the grain size. And another reason is that in many previous studies the interaction between the other microstructural parameters has not been considered.

The purpose of this paper is to investigate the compressive and tensile strength, physical and engineering index parameters of selected dolomitic rocks with emphasis on grain size. For this purpose three groups of dolomite with similar mineralogical compositions were selected; fine grain, medium grain and coarse grain. Three sets of experiments are performed on 32 samples: first, petrography tests for determining mineral composition and microstructure of rock containing grain size and grain size distribution; second, experiments to determine the physical properties of the rocks included density, compressional and shear wave velocity, and the third category of experiments included uniaxial compressive strength tests, Brazilian tensile strength and point load strength.

\section{Sampling sites}

Dolomite is one of the most important mineral constituents of carbonate rock in northwestern of Iran. After assessing satellite and geological maps it was determined that two rock formations were suitable for sampling; Soltanieh formation with the geographical coordinates of $36^{\circ} 36^{\prime} 24^{\prime \prime} \mathrm{N}$ and $48^{\circ} 13^{\prime} 45^{\prime \prime} \mathrm{E}$ and Elika Formation at the geographic coordinates of $36^{\circ} 41^{\prime} \mathrm{N}$ and $48^{\circ} 03^{\prime} \mathrm{E}$; in Zanjan province, northwestern of Iran (Figure 1). Soltanieh formation had a thickness of 985 meters, which in lithological terms, consisted of medium to thick layers of dolomite, light gray to dark gray in color with narrow layers of green shale. Elika formation consisted of almost 35 meters of carbonate rock. This formation, was divisible into two major parts: 1) the lower part with a thickness of almost 2 meters, mainly formed of calcareous conglomerates and 2) an upper part formed of thin-bedded layers of dolomite with a yellow-gray color and a thickness of 33 meters.

\section{Sampling and experimental procedures}

32 samples were cored from blocks with no apparent signs of weathering and without evidence of macroscopic heterogeneity such as veins and joints. As already mentioned three groups of dolomites with different grain sizes were selected; fine grain, medium grain and coarse grain.

\subsection{Petrographic and mineralogical analysis}

Microscopic thin sections with thickness of $30 \mu \mathrm{m}$ were taken from each of the three groups of dolomites and in order to classify samples a classification procedure of Gregg and Sibley (1984), Sibley and Gregg (1987) and Mazzullo (1992) was used. Also mineralogical composition of the rocks for 5 samples was taken by X-ray diffraction device (Figure 2 and Table 1):

1. Fine grain dolomite. In accordance with the petrographic observations, fine grain dolomite are composed of anhedral, very fine grain to fine grain with inter-granular boundary of non-planer. Dolomite grain size in this group are smaller than $20 \mu \mathrm{m}$ (average grain size is $9 \mu \mathrm{m}$ ) and grain size distribution is uniform. This group of dolomites is usually dense and dark grey in colour. Sometimes this type of dolomite has individual fine grains of quartz and calcite (approximately 1 to 4 percent). This group of 


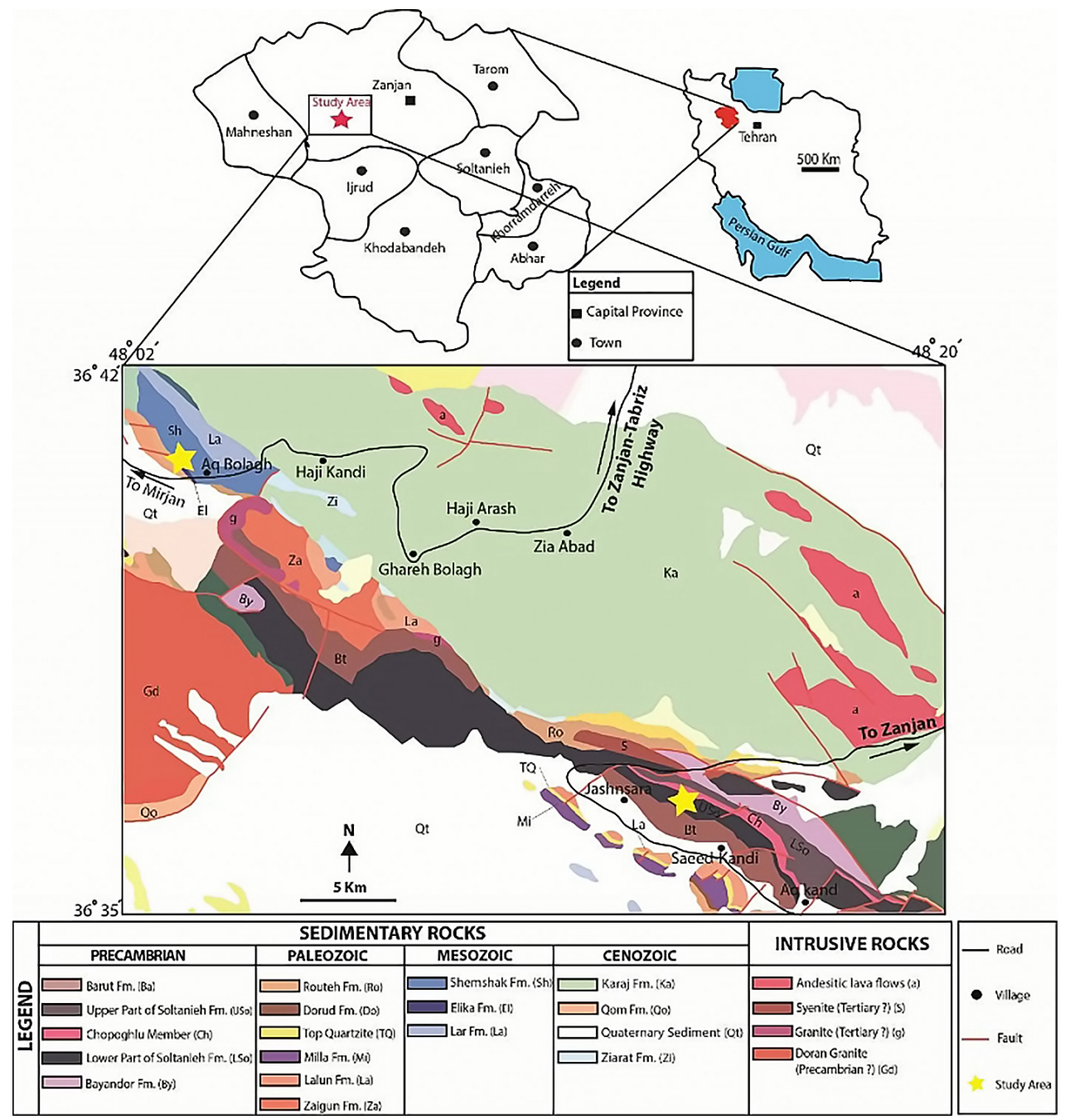

Figure 1. The geological map and geographical location of the study area (geological map modified from Hajian and Zahedi (2004))

a)

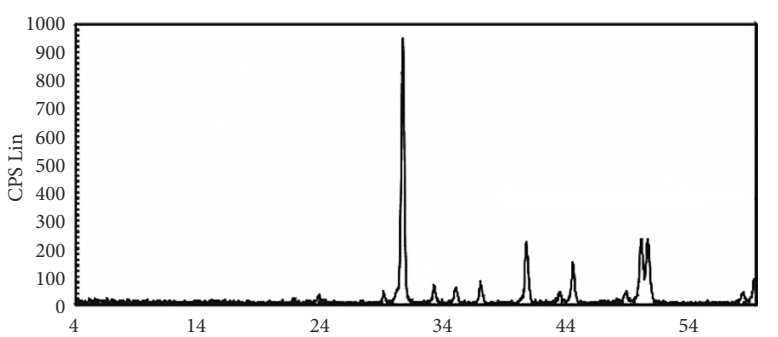

c)

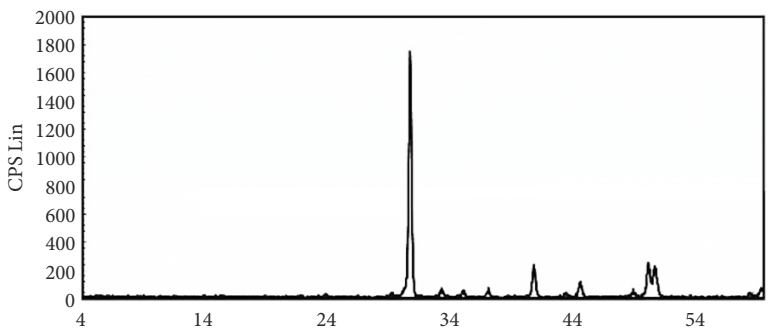

b)

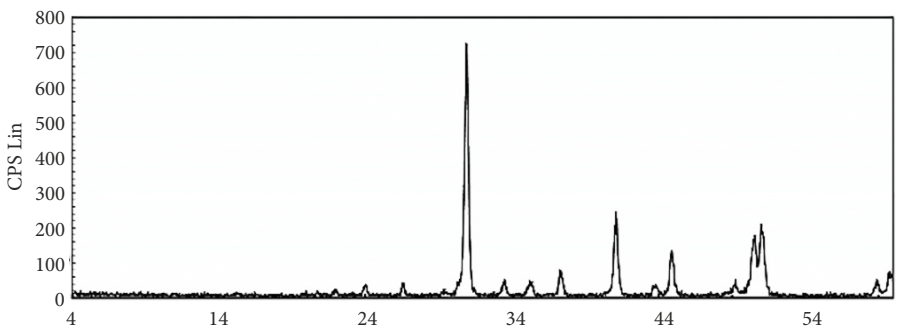

d)

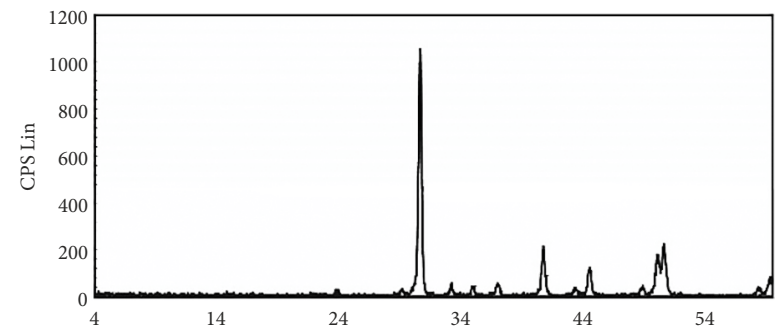

Figure 2. Results for dolomite samples studied by X-ray diffraction analysis (XRD): (a) Fine grain dolomite (Soltanieh Formation); (b) Fine grain dolomite (Elika Formation); (c) Medium grain dolomite (Soltanieh Formation);

(d) Coarse Grain dolomite (Soltanieh Formation) 
dolomites can be named dolomicrite, because of its fine grain size. This type of dolomite is equivalent to non-planer (Mazzullo, 1992) and xenotopic in texture (Gregg \& Sibley, 1984). The characteristics of a sample of this dolomite is presented in Table 1.

2. Medium grain dolomite. Medium grain dolomite mainly consists of dense and subhedral grains with inter-granular boundaries of planer-s (Table 1). Dolomite grain size varies between $20 \mu \mathrm{m}$ to $100 \mu \mathrm{m}$ ( $42 \mu \mathrm{m}$ on average). This dolomite is known as dolomicrosparite. It has hypidiotopic (Gregg \& Sibley, 1984) and planer-s texture (Mazzullo, 1992).

3. Coarse grain dolomite. Coarse grain dolomite has grain size between $100 \mu \mathrm{m}$ to $500 \mu \mathrm{m}(120 \mu \mathrm{m}$ on average). These dolomites is known as dolosparite due to their size and are composed of dense and coarse subhedral grain with non-uniform distribution size. The texture of this dolomite is equivalent to hypidiotopic (Mazzullo, 1992) and planer-s texture (Gregg \& Sibley, 1984) (Table 1). Results of petrographic studies demonstrated that grain size distribution in dolomite becomes more non-uniform with increasing grain size. This can be related to heterogeneous dispersion of dolomite grain formation, multi-stage formation and non-uniform growth of fine grains.

\subsection{Physical and mechanical testing procedure}

After petrographic observations, experimental tests for determining physical characteristics (density, compres- sional and shear wave velocity) and compressive and tensile strength of dolomites by uniaxial compressive strength (UCS), Brazilian tensile strength (BTS) and point load strength $\left(I_{s(50)}\right)$, for 32 samples according to International Society for Rock Mechanics and Rock Engineering [ISRM] standards were conducted. To perform the uniaxial compressive strength test, 32 cylindrical samples were cored from the selected blocks; these were $54 \mathrm{~mm}$ in diameter with a length to diameter ratio of approximately of 2.5. The cut end faces of cores were smoothed and made perpendicular to the core axes with a polishing and lapping machine based on ISRM (1979a) requirements (Figure 3(d)). Uniaxial compressive strength tests were conducted by DARTEC-9600 servo-control machine with load frame of $2000 \mathrm{kN}$ capacity (Figure 3(a)) at a constant rate of $0.002 \mathrm{~mm} / \mathrm{sec}$. Applied loads and axial strain is measured automatically by the machine automatically, but the lateral strain is measured by installing three strain gauges around the sample and connecting them to the data logger (Figure 4). By plotting the stress against the axial strain and lateral strain curves for each sample, the peak strength (uniaxial compressive strength), Poisson's ratio and average Young's modulus of elasticity are obtained.

Compressional and shear wave velocity were measured by separated transducers using a Sonic viewer device, Figures 3(b) and 3(c) illustrate this experiment and transducers. In point load test, samples can be loaded axially or diagonally. In this test, loading was continued until failure occurred in the sample, at this moment, the point load strength was equivalent to (ISRM, 1985):

Table 1. Characteristics of three samples of the fine, medium and coarse grain dolomite rocks based on petrographic and XRD analysis

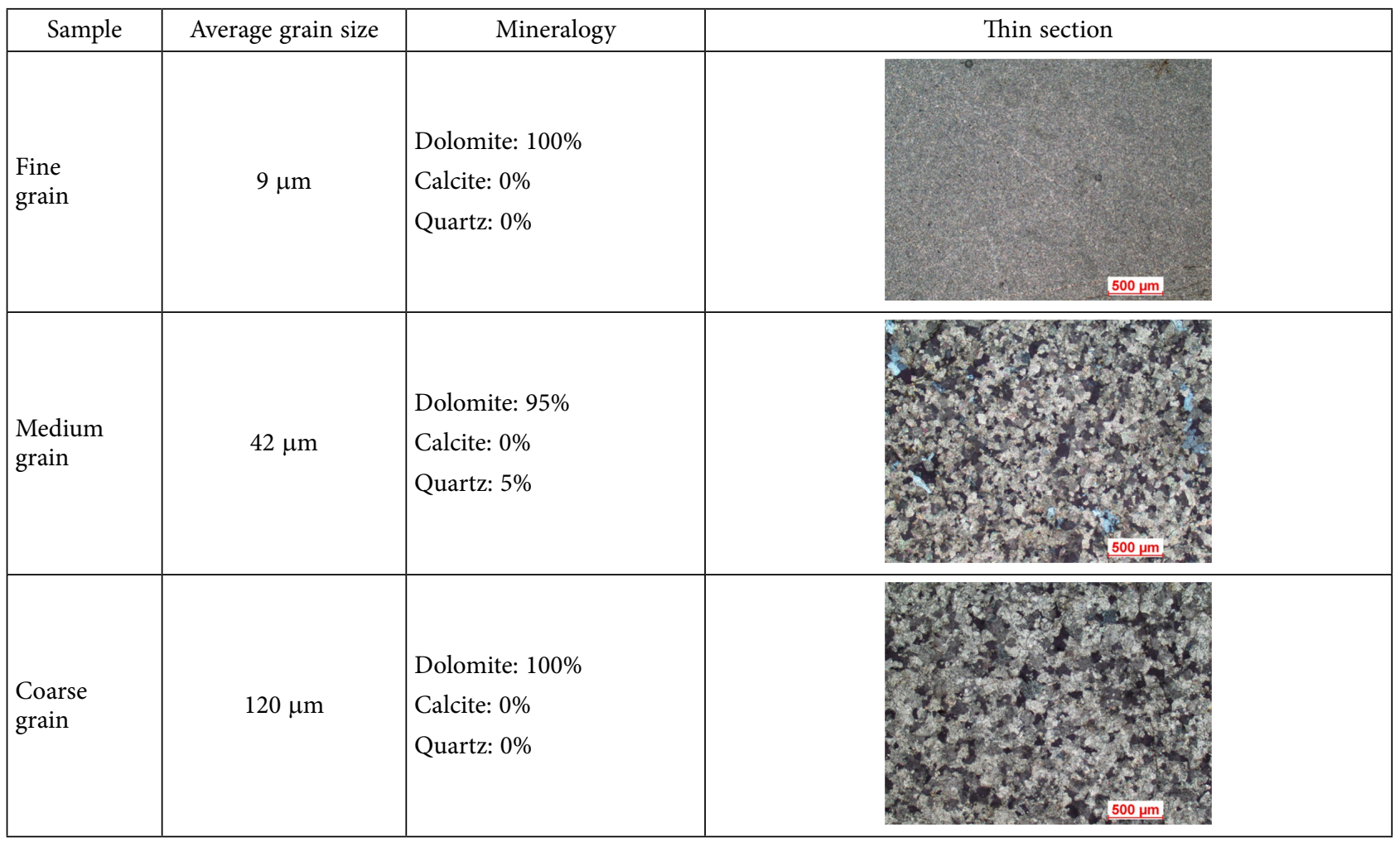




$$
I_{s(50)}=F\left(\frac{P}{D_{e}^{2}}\right),
$$

where $D_{e}^{2}=\frac{4 A}{\pi}, A=W D$ is the minimum cross sectional area of a plane through the loading points, and $F=\left(\frac{D_{e}}{50}\right)^{0.45}$ is the size correction factor, and $P$ is the load at failure.

Brazilian tensile strength test is used for indirect determination of tensile strength of cylindrical samples of brittle materials such as rock and concrete. The test was conducted according to ISRM (1978) standard using the loading machine with a $600 \mathrm{kN}$ loading capacity and a constant loading rate of $0.2 \mathrm{kN} / \mathrm{s}$. Tensile strength was calculated by (ISRM, 1979b):

$$
\mathrm{BTS}=\frac{2 P}{\pi D t}=0.636 \frac{P}{D t},
$$

where $P$ is failure load, and $D$ and $t$ are diameter and thickness of the specimens respectively.

\section{Results and discussion}

The results of engineering index properties such as density, compressional wave and shear wave velocities, elastic properties and strength of selected samples such as point load strength, Brazilian tensile strength, uniaxial compressive strength, average Young's modulus and Poisson's ratio are presented in Table 2.

According to the results, the values of density of samples ranges between $2.53-2.74 \mathrm{gr} / \mathrm{cm}^{3}$ with the mean of $2.63 \mathrm{gr} / \mathrm{cm}^{3}$ that indicated the dolomites have a high density.
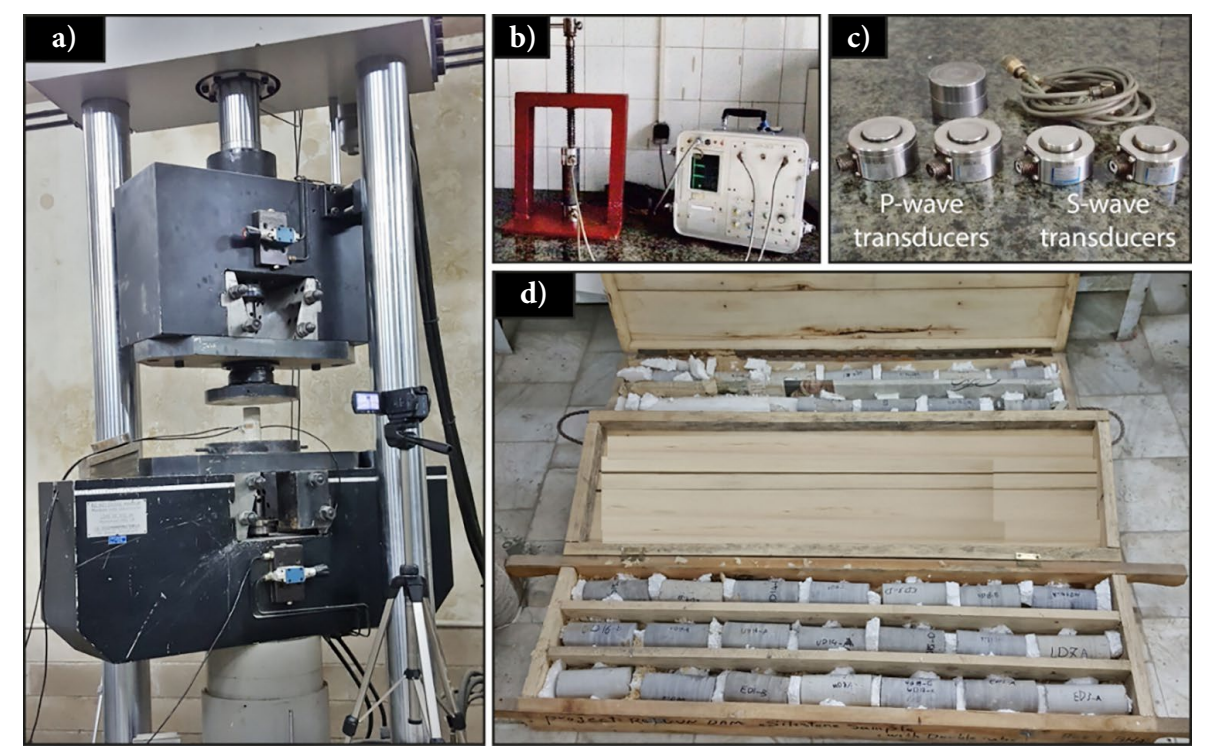

Figure 3. (a) DARTEC-9600 servo-control machine, used to uniaxial compressive strength tests;

(b) apparatus for wave velocity measurement; (c) transducers, cables and spears; (d) dolomite samples
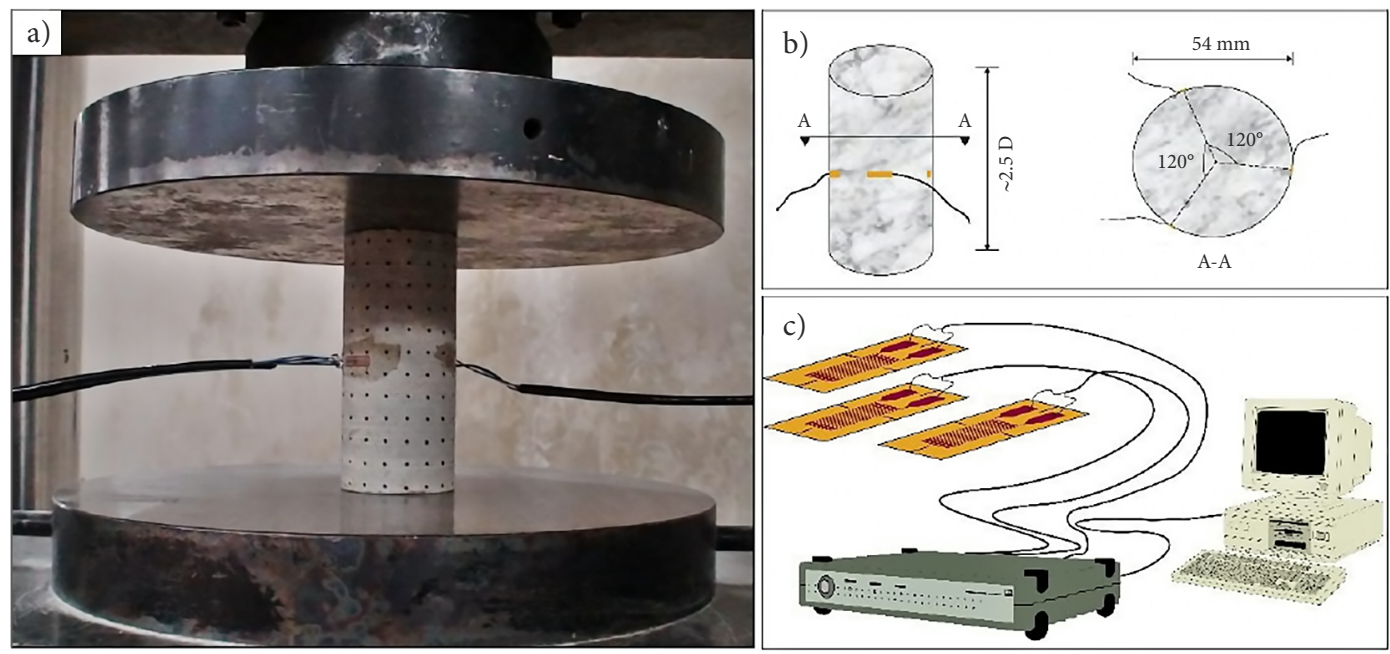

Figure 4. (a) Sample placed between two steel plates of compressive strength test machine; (b) position of three strain gauges around the sample to measure lateral strain; (c) display the connection of strain gauges to the data logger 
Table 2. Results of physical and mechanical tests conducted on dolomite samples

\begin{tabular}{|c|c|c|c|c|c|c|c|c|c|c|c|c|c|}
\hline & $\mathrm{SN}$ & GS & $r$ & $V_{p}$ & $V_{s}$ & $E_{\text {ave }}$ & $v$ & UCS & BTS & $I_{s(50)}$ & $\frac{\mathrm{UCS}}{\mathrm{BTS}}$ & $\frac{\mathrm{UCS}}{I_{s(50)}}$ & $\frac{\mathrm{BTS}}{I_{s(50)}}$ \\
\hline \multirow{12}{*}{ 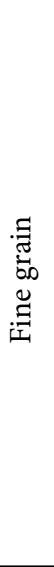 } & $\mathrm{F} 1$ & 20 & 2.72 & 3893 & 2224 & 27.01 & 0.17 & 31.84 & 4.1 & 3.15 & 7.77 & 10.11 & 1.30 \\
\hline & F2 & 10 & 2.66 & 4671 & 2856 & 32.90 & 0.38 & 27.62 & 3.5 & 2.57 & 7.89 & 10.75 & 1.36 \\
\hline & F3 & 10 & 2.74 & 5092 & 3260 & 34.33 & 0.18 & 24.69 & 3.28 & 2.41 & 7.53 & 10.24 & 1.36 \\
\hline & $\mathrm{F} 4$ & 15 & 2.65 & 5236 & 2839 & 31.96 & 0.39 & 22.65 & 3.13 & 2.17 & 7.24 & 10.44 & 1.44 \\
\hline & F5 & 15 & 2.66 & 5474 & 2980 & 31.98 & 0.17 & 20.37 & 2.8 & 2.73 & 7.27 & 7.46 & 1.03 \\
\hline & F6 & 5 & 2.71 & 5796 & 3000 & 55.83 & 0.14 & 16.38 & 2.47 & 1.67 & 6.63 & 9.81 & 1.48 \\
\hline & F7 & 5 & 2.70 & 5662 & 2993 & 28.64 & 0.31 & 24.47 & 3.8 & 2.86 & 6.44 & 8.56 & 1.33 \\
\hline & F8 & 5 & 2.71 & 5665 & 2771 & 33.62 & 0.29 & 25.97 & 3.42 & 2.15 & 7.30 & 11.62 & 1.59 \\
\hline & F9 & 5 & 2.67 & 4307 & 2732 & 24.16 & 0.25 & 20.48 & 2.74 & 1.71 & 7.48 & 11.98 & 1.60 \\
\hline & F10 & 5 & 2.66 & 4600 & 2603 & 19.72 & 0.26 & 14.26 & 1.91 & 1.65 & 7.46 & 8.64 & 1.16 \\
\hline & F11 & 5 & 2.64 & 4479 & 2439 & 13.96 & NA & 9.18 & 1.81 & 1.43 & 5.07 & 6.42 & 1.27 \\
\hline & F12 & 5 & 2.66 & 4563 & 2677 & 16.22 & NA & 10.30 & 1.73 & 1.05 & 5.95 & 9.81 & 1.65 \\
\hline \multirow{9}{*}{ 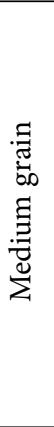 } & M1 & 40 & 2.61 & 4749 & 2680 & 30.39 & NA & 43.93 & 7.68 & 5.66 & 5.72 & 7.76 & 1.36 \\
\hline & M2 & 60 & 2.59 & 5091 & 2901 & 47.49 & 0.11 & 32.31 & 2.49 & 1.83 & 12.98 & 17.66 & 1.36 \\
\hline & M3 & 35 & 2.65 & 6010 & 3262 & 46.61 & 0.28 & 39.37 & 4.15 & 2.91 & 9.49 & 13.53 & 1.43 \\
\hline & M4 & 35 & 2.65 & 5824 & 3307 & 75.67 & 0.13 & 30.10 & 1.82 & 1.59 & 16.54 & 18.93 & 1.14 \\
\hline & M5 & 35 & 2.63 & 6231 & 3143 & 37.80 & 0.33 & 34.01 & 3.78 & 2.23 & 9 & 15.25 & 1.70 \\
\hline & M6 & 35 & 2.64 & 5643 & 3128 & 45.60 & 0.38 & 32.52 & 3.56 & 2.15 & 9.13 & 15.13 & 1.66 \\
\hline & M7 & 35 & 2.64 & 5739 & 2918 & 42.08 & 0.43 & 35.22 & 4.15 & 3.43 & 8.49 & 10.27 & 1.21 \\
\hline & M8 & 50 & 2.63 & 4717 & 2867 & 36.79 & 0.34 & 27.67 & 1.63 & 1.32 & 16.98 & 20.96 & 1.23 \\
\hline & M9 & 50 & 2.66 & 5148 & 2906 & 65.58 & 0.36 & 43 & 5.74 & 4.88 & 7.41 & 8.72 & 1.18 \\
\hline \multirow{11}{*}{ 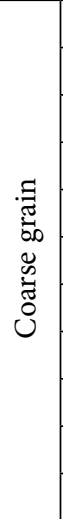 } & $\mathrm{C} 1$ & 110 & 2.58 & 4217 & 2404 & 44.37 & 0.10 & 44.93 & 4.63 & 3.23 & 9.70 & 13.91 & 1.43 \\
\hline & $\mathrm{C} 2$ & 110 & 2.59 & 4538 & 2512 & 55.56 & 0.10 & 63.51 & 7.03 & 4.49 & 9.03 & 14.15 & 1.57 \\
\hline & C3 & 110 & 2.54 & 4144 & 2407 & 42.70 & 0.43 & 48.70 & 6.43 & 4.45 & 7.57 & 10.94 & 1.44 \\
\hline & $\mathrm{C} 4$ & 110 & 2.58 & 4399 & 2597 & 50.65 & 0.33 & 45.66 & 4.23 & 2.47 & 10.80 & 18.49 & 1.71 \\
\hline & C5 & 100 & 2.54 & 4472 & 2636 & 46.57 & 0.16 & 39.38 & 3.29 & 1.65 & 11.97 & 23.86 & 1.99 \\
\hline & C6 & 100 & 2.53 & 4235 & 2323 & 34.64 & 0.33 & 40.31 & 3.5 & 2.06 & 11.52 & 19.57 & 1.70 \\
\hline & C7 & 100 & 2.54 & 4391 & 2484 & 46.05 & 0.21 & 38.65 & 3.25 & 2.57 & 11.89 & 15.04 & 1.26 \\
\hline & C8 & 100 & 2.57 & 4394 & 2716 & 51.58 & 0.44 & 38.06 & 4.62 & 2.05 & 8.24 & 18.56 & 2.25 \\
\hline & C9 & 160 & 2.61 & 5754 & 3131 & 74.72 & 0.20 & 83.81 & 10.04 & 7.38 & 8.35 & 11.36 & 1.36 \\
\hline & C10 & 160 & 2.58 & 6124 & 3377 & 51.61 & 0.19 & 65.82 & 9.08 & 6.23 & 7.25 & 10.56 & 1.46 \\
\hline & $\mathrm{C} 11$ & 160 & 2.60 & 6172 & 3125 & 76.52 & 0.41 & 65.45 & 5.92 & 3.83 & 11.06 & 17.09 & 1.55 \\
\hline
\end{tabular}

Notes: $\mathrm{SN}$ - sample number; GS - grain size $(\mu \mathrm{m}) ; \rho$ - density $\left(\mathrm{gr} / \mathrm{cm}^{3}\right) ; V_{p}, V_{s}$ - compressional and shear wave velocity $(\mathrm{m} / \mathrm{s}) ; E_{\text {ave }}-$ average Young's modulus (GPA); $v$ - Poisson's ratio; UCS - uniaxial compressive strength (MPa); BTS - Brazilian tensile strength $(\mathrm{MPa}) ; I_{s(50)}$ - point load strength (MPA).

The compressional wave velocities vary between 3893 to $6231 \mathrm{~m} / \mathrm{s}$ and the mean value is $5045 \mathrm{~m} / \mathrm{s}$. The shear wave velocities also range between 2224 to $3377 \mathrm{~m} / \mathrm{s}$ and the mean value is $2819 \mathrm{~m} / \mathrm{s}$. Pickett (1963), based on experimental tests on carbonate reservoirs, represented that ratio of shear wave to compressional wave velocity in different rocks is a constant and for dolomite and limestone is 1.8 and 1.9 respectively. In the current study, these ratios for fine grain, medium grain and coarse grain dolomite and averages of samples are 1.78, 1.81, 1.77 and 1.79, respectively.

Average Young's modulus is between 14 to $76.5 \mathrm{GPa}$, with the mean of $42.3 \mathrm{GPa}$. Poisson's ratio varies between
0.1 and 0.44 for the studied samples with a mean of 0.27 .

Uniaxial compressive strength is from 9.18 to 83.81 $\mathrm{MPa}$ and with the mean of $35.64 \mathrm{MPa}$, based on ANON's (1979) classification, $81.3 \%$ of the samples are moderately strong, $12.5 \%$ are strong and $6.2 \%$ are weak. The measured of the Brazilian tensile strength for the samples is between 1.63 and $10.04 \mathrm{MPa}$, and the mean value is $4.12 \mathrm{MPa}$. Also, the measured values of the point load strength $\left(I_{s(50)}\right)$ ranges between 1.05 and $7.38 \mathrm{MPa}$ with the mean of $2.87 \mathrm{MPa}$. According to classification of Broch and Franklin (1972), which is based on point load strength, $72 \%$ of the samples have high strength and $28 \%$ of the samples have very high strength. 
A review of the technical literature shows that the ratio of uniaxial compressive strength to tensile strength in various rocks varies from 10 to 50 . In this study, this ratio for fine grain, medium grain and coarse grain dolomite samples are 7, 10.64 and 9.76 , respectively and average of all samples is almost 9. Also, uniaxial compressive strength ratio to the point load strength based on previous research depending on the type of rock, mineral composition and petrographic characteristics ranges from 5 to 30 (Zhang, 2016) and in this study for fine, medium and coarse grain dolomite samples are 9.65, 14.25 and 15.78, respectively and average for all is almost 13 . Zhang (2016) offered BTS $/ I_{s(50)}$ ratio as 1.5 and in this study this ratio for fine, medium and coarse grain dolomite and averages of all samples are 1.38, 1.36, 1.61 and 1.45, respectively.

\subsection{Effect of grain size on the mechanical and physical properties}

Some of the results presented in Table 2 are shown in Figure 5. As can be seen in Figure 5(f), the density of the fine grain specimens is slightly higher than the coarse grain specimens (up to $4 \%$ ), therefore there is a negative strong correlation between density and grain size $(r=-0.77)$. Eberhardt et al. (1999) also found that density decreases with increasing grain size, for selected granite rocks. Based on the simple linear regression performed, the following empirical relationship between density $\left(\mathrm{gr} / \mathrm{cm}^{3}\right)$ and grain size $(\mu \mathrm{m})$ for selected dolomites is suggested (Figure 6):

$$
\rho=-0.0008 \text { GS }+2.676 \text {. }
$$

a)

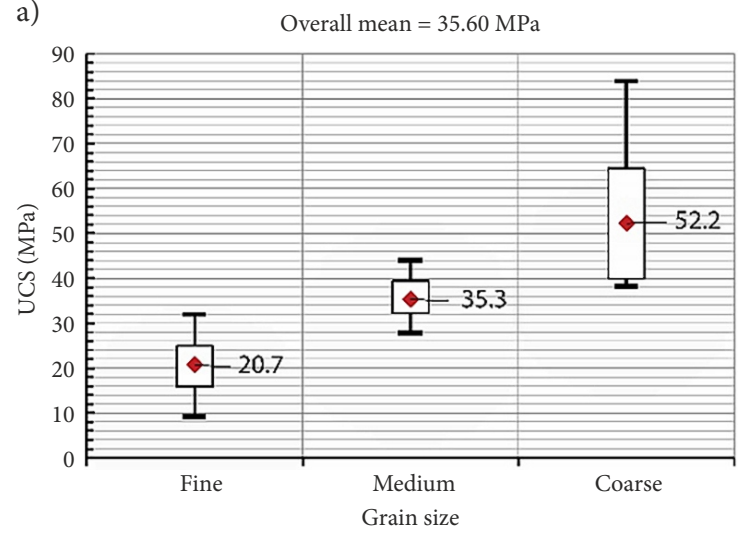

c)

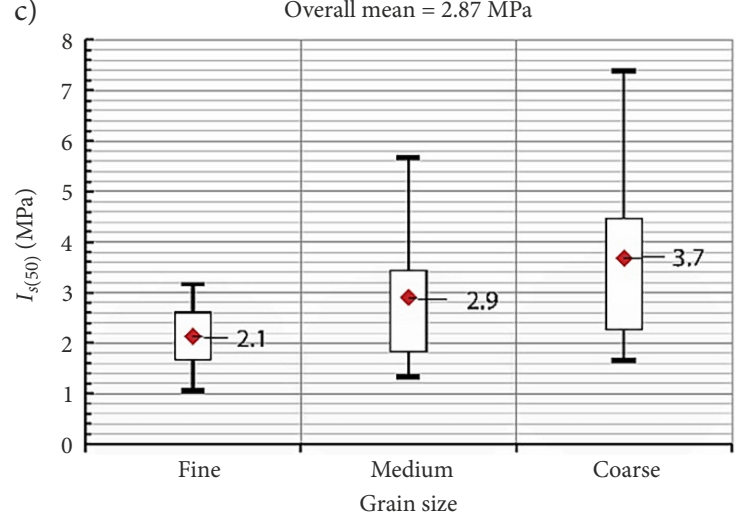

e)

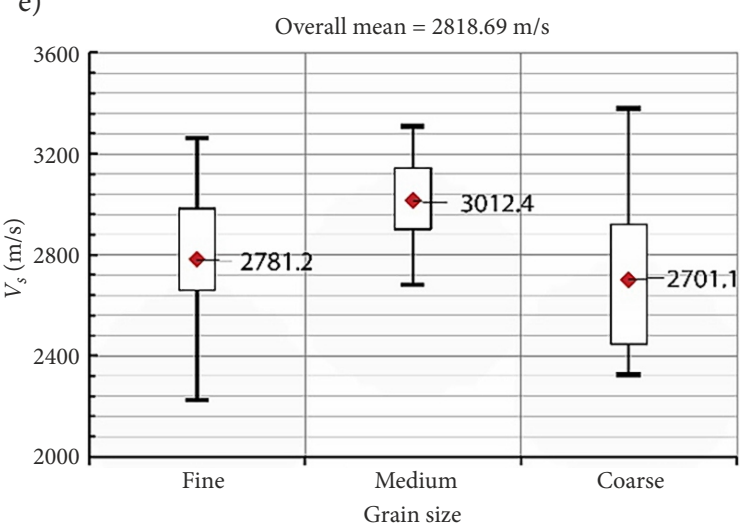

b)

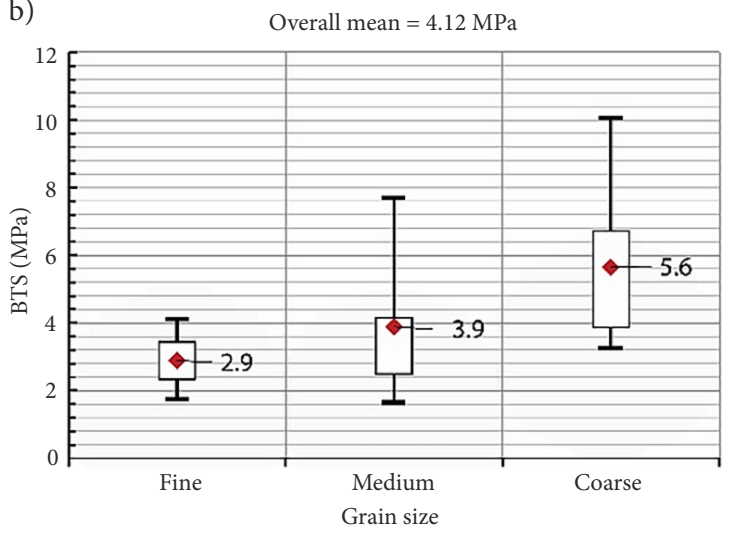

d)

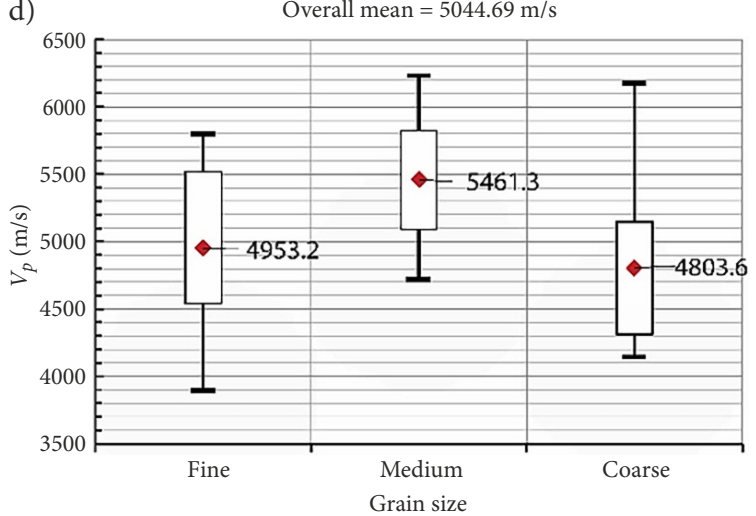

f)

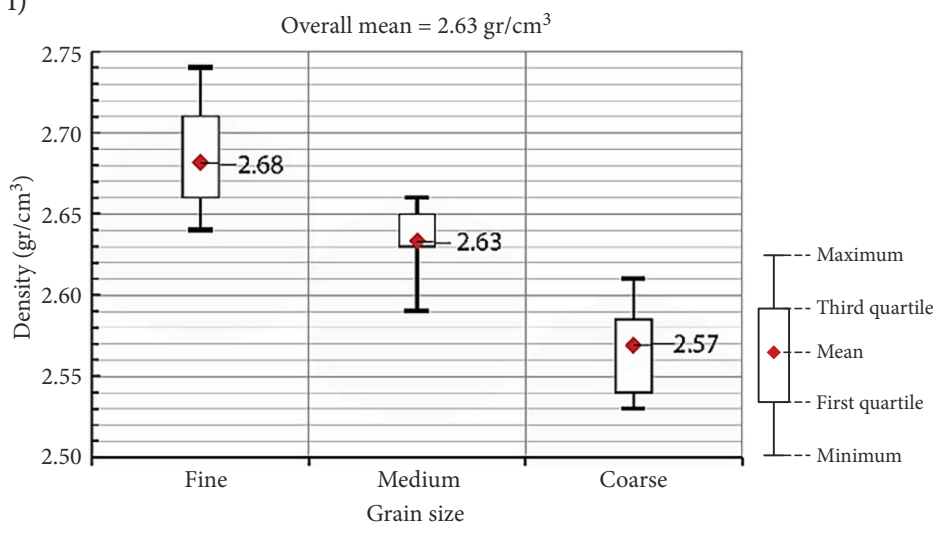

Figure 5. Effect of grain size on the mechanical and physical properties of the dolomite samples. grain size versus:

(a) Uniaxial compressive strength (UCS); (b) Brazilian tensile strength (BTS); (c) Point load strength $\left(I_{s(50)}\right)$;

(d) P-wave velocity $\left(V_{p}\right)$; (e) S-wave velocity $\left(V_{s}\right)$; and (f) density 
Also according to Figures 5(a), 5(b) and 5(c) it is observed that with increasing grain size, compressive and tensile strength increases, and grain size has a significant positive correlation with the uniaxial compressive strength $(r=0.89)$, Brazilian tensile strength $(r=0.69)$ and point load strength $(r=0.58)$. The result is inconsistent with the results for granite rocks and similar to that for clastic rocks. Sample of selected dolomitic rocks approximately are monomineralic, major mineral is dolomite and calcite is the minor mineral with low abundance, the only stressbearing components in loading are the grains, thus, as the grain size increases, the sample tensile and compressive strength increases. The following two relationships are recommended for uniaxial compressive strength $(\mathrm{MPa})$ versus grain size (Figure 7), and Brazilian tensile strength $(\mathrm{MPa})$ versus grain size $(\mu \mathrm{m})$ :

$$
\begin{aligned}
& \mathrm{UCS}=0.292 \mathrm{GS}+19.195 ; \\
& \mathrm{BTS}=0.028 \mathrm{GS}+2.54 .
\end{aligned}
$$

In the case of the elastic properties of materials, there is a good correlation between the average Young's modulus and the grain size $(r=0.64)$, but there is no relationship between the Poisson's ratio and the grain size for

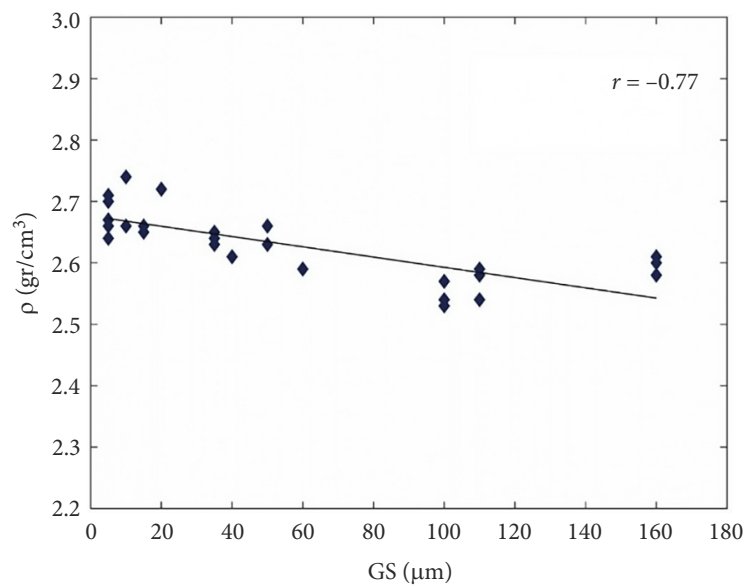

Figure 6. Density versus grain size (GS)

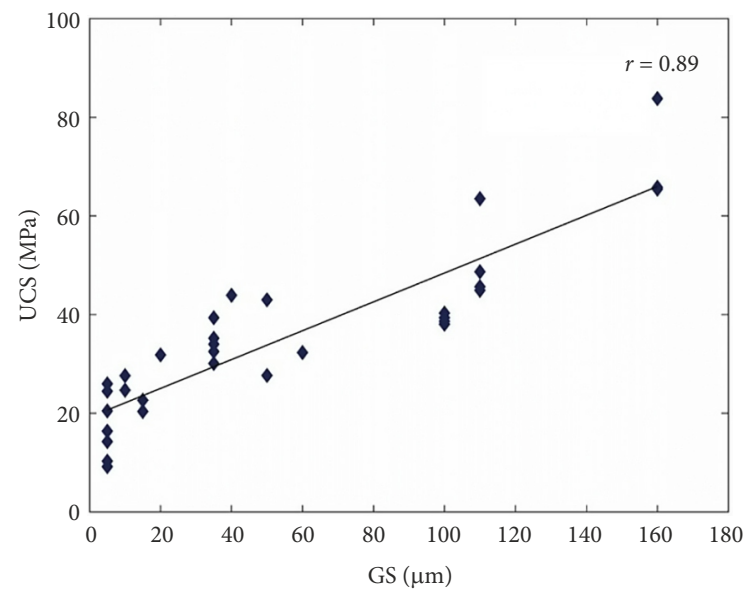

Figure 7. Uniaxial compressive strength (UCS) versus grain size $(\mathrm{GS})$ selected dolomite samples. The relationship between average Young's modulus (GPa) and grain size $(\mu \mathrm{m})$ can be expressed using this relationship:

$$
E_{\text {ave }}=0.202 \mathrm{GS}+30.93 \text {. }
$$

It is observed that averages of compressional and shear wave velocities for fine and coarse grain samples are almost $9 \%$ and $12 \%$ lower than those for the medium grain samples respectively (Figures 5(d), 5e and Table 2). For this reason, there is no correlation between grain size and compressional and shear wave velocity. Eberhardt et al. (1999) also did not find a clear relationship between wave velocity and grain size.

In the following and based on the simple linear regression performed, it can be seen that the compressional wave velocity $(\mathrm{m} / \mathrm{s})$ has a strong positive correlation with the shear wave velocity $(r=0.88)$ (Figure 8 ):

$$
V_{p}=2.006 V_{s}-610.747 \text {. }
$$

Compressional wave velocity and shear wave velocity also have a moderate correlation with average Young's modulus $(r=0.43)$. The average Young's modulus (GPa) has also significant correlation versus uniaxial compres-

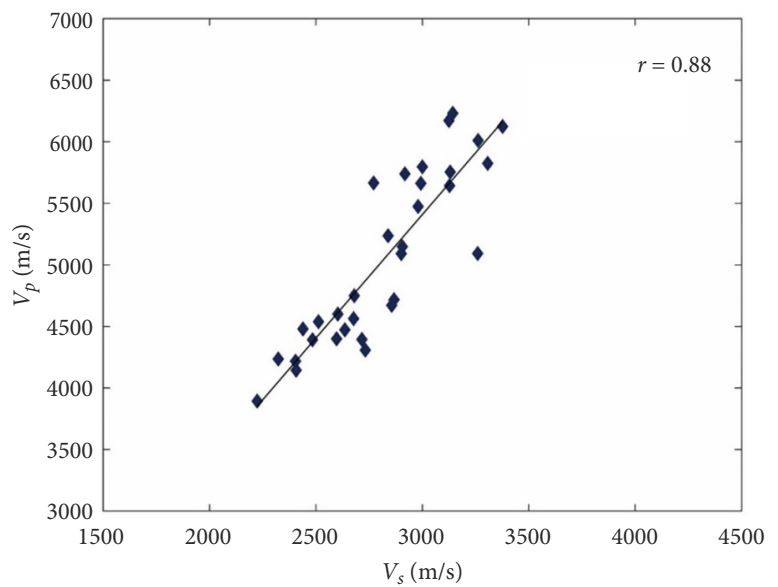

Figure 8. Compressional wave velocity versus shear wave velocity

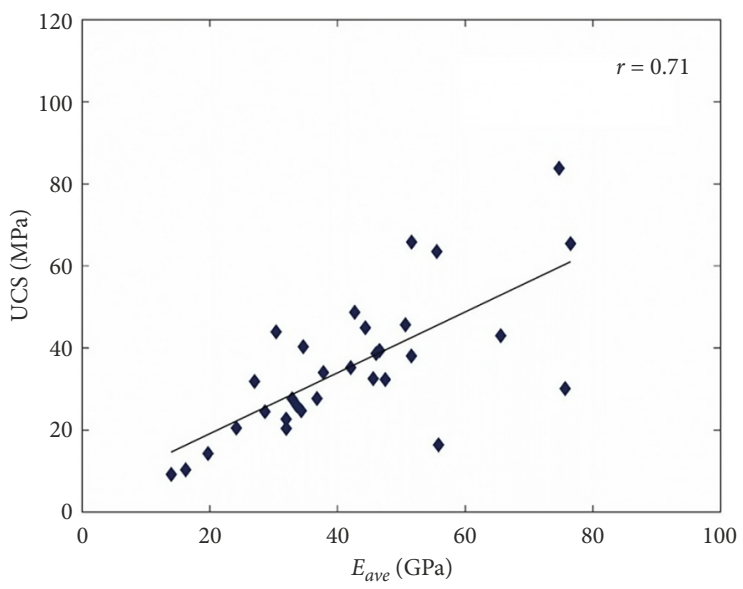

Figure 9. Uniaxial compressive strength (UCS) versus average Young's modulus 
sive strength (MPa) $(r=0.71)$ (Figure 9) and moderately correlates with point load strength $(r=0.45)$ and Brazilian tensile strength $(r=0.48)$.

$$
\mathrm{UCS}=0.742 E_{\text {ave }}+4.247 \text {. }
$$

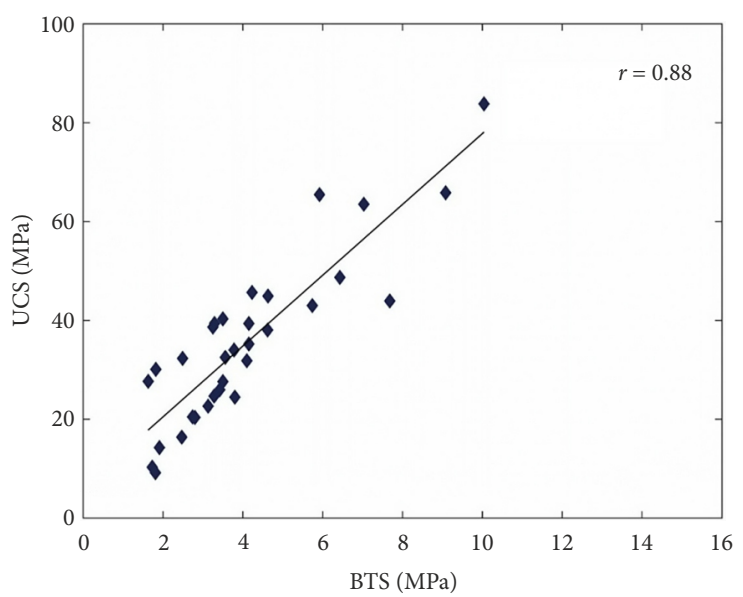

Figure 10. Uniaxial compressive strength (UCS) versus Brazilian tensile strength (BTS)

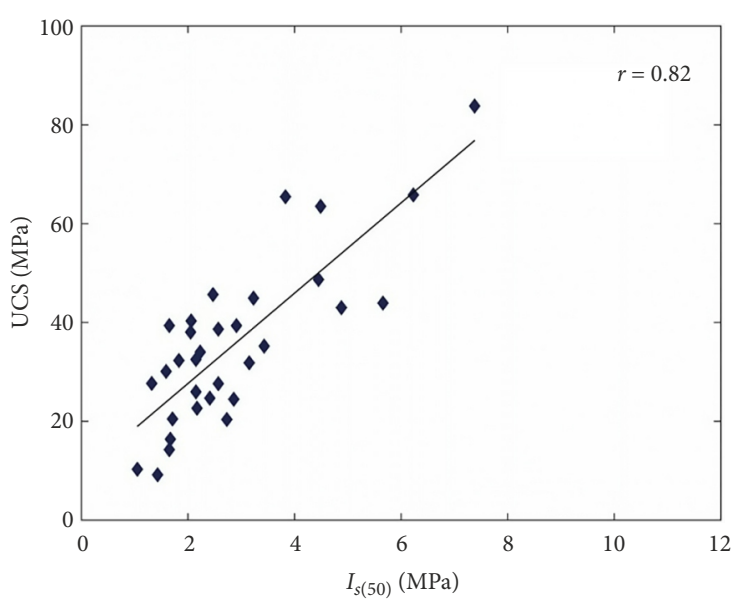

Figure 11. Uniaxial compressive strength (UCS) versus point load strength

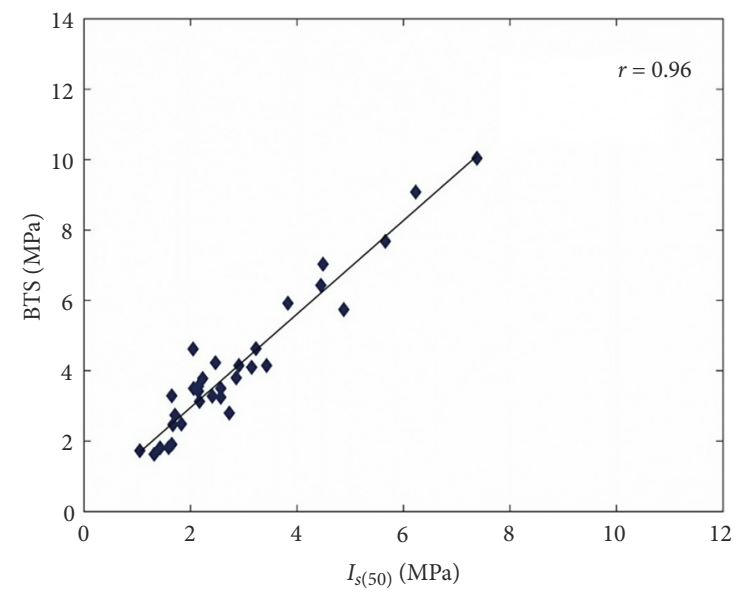

Figure 12. Brazilian tensile strength (BTS) versus point load strength
There is a strong correlation between uniaxial compressive strength and Brazilian tensile strength $(r=0.88)$ (Figure 10). There are similar relationships between uniaxial compressive strength and point load strength $(r=$ 0.82) (Figure 11) and Brazilian tensile strength versus point load strength $(r=0.96)$ (Figure 12). Figures 6 to 12 illustrate some of these relationships. The following three empirical relationships show the relationship between these three strength:

$$
\begin{aligned}
& \mathrm{UCS}=7.165 \mathrm{BTS}+6.153 ; \\
& \mathrm{UCS}=9.14 I_{s(50)}+9.38 ;(10) \\
& \mathrm{BTS}=1.33 I_{s(50)}+0.30 .
\end{aligned}
$$

\section{Conclusions}

The laboratory studies performed in this paper showed part of the relationship between microstructure of selected dolomite rock samples and their physical, mechanical and engineering index properties. In previous studies, the effect of grain size on peak strength was more controversial, and this article has emphasized this issue. Important results are listed below:

1. According to petrographic results, with increasing grain size, their distribution becomes more nonuniform.

2. There are significant positive correlation between grain size and uniaxial compressive strength $(r=$ $0.89)$, point load strength $(r=0.58)$, Brazilian tensile strength $(r=0.69)$, and average Young's modulus $(r=0.64)$.

3. With increasing grain size and with a high correlation coefficient $(r=-0.77)$ density decreases.

4. There is strong correlation between compressional wave velocity and shear velocity $(r=0.88)$.

5 . There is a strong correlation between uniaxial compressive strength versus Brazilian tensile strength $(r=0.88)$, uniaxial compressive strength versus point load strength $(r=0.82)$, and Brazilian tensile strength versus point load strength $(r=0.96)$.

6. Ratios of uniaxial compressive strength to Brazilian tensile strength for fine, medium and coarse grain dolomite samples were 7, 10.64 and 9.76 respectively.

7. Ratios of uniaxial compressive strength to point load strength for fine grain, medium grain and coarse grain dolomite were 9.65, 14.25 and 15.78 respectively and ratios of Brazilian tensile strength to point load strength for fine grain, medium grain and coarse grain dolomite samples were 1.38, 1.36 and 1.61 , respectively.

\section{References}

Ajalloeian, R., Mansouri, H., \& Baradaran, E. (2017). Some carbonate rock texture effects on mechanical behavior, based on Koohrang tunnel data, Iran. Bulletin of Engineering Geology and the Environment, 76(1), 295-307.

https://doi.org/10.1007/s10064-016-0861-y 
Aladejare, A. D. (2020). Evaluation of empirical estimation of uniaxial compressive strength of rock using measurements from index and physical tests. Journal of Rock Mechanics and Geotechnical Engineering, 12(2), 256-268.

https://doi.org/10.1016/j.jrmge.2019.08.001

Amann, F., Ündül, Ö., \& Kaiser, P. K. (2014). Crack initiation and crack propagation in heterogeneous sulfate-rich clay rocks. Rock Mechanics and Rock Engineering, 47(5), 1849-1865. https://doi.org/10.1007/s00603-013-0495-3

ANON. (1979). Classification of rocks and soils for engineering geological mapping. Part I - Rock and soil materials. Bulletin of the International Association of Engineering Geology, 19, 364-371. https://doi.org/10.1007/BF02600503

Blott, S. J., \& Pye, K. (2001). GRADISTAT: a grain size distribution and statistics package for the analysis of unconsolidated sediments. Earth Surface Processes and Landforms, 26(11), 1237-1248. https://doi.org/10.1002/esp.261

Broch, E., \& Franklin, J. A. (1972). The point load strength test. International Journal of Rock Mechanics and Mining Science, 9, 669-697. https://doi.org/10.1016/0148-9062(72)90030-7

Eberhardt, E., Stimpson, B., \& Stead, D. (1999). Effects of grain size on the initiation and propagation thresholds of stressinduced brittle fractures. Rock Mechanics and Rock Engineering, 32(2), 81-99. https://doi.org/10.1007/s006030050026

Farrokhrouz, M., \& Asef, M. R. (2017) Experimental investigation for predicting compressive strength of sandstone. Journal of Natural Gas Science and Engineering, 43, 222-229.

https://doi.org/10.1016/j.jngse.2017.03.023

Festa, V., Fiore, A., Luisi, M., Miccoli, M. N., \& Spalluto, L. (2018). Petrographic features influencing basic geotechnical parameters of carbonate soft rocks from Apulia (southern Italy). Engineering Geology, 233, 76-97.

https://doi.org/10.1016/j.enggeo.2017.12.009

Fredrich, J. T., Evans, B., \& Wong, T. F. (1990). Effect of grain size on brittle and semi brittle strength: Implications for micromechanical modelling of failure in compression. Journal of Geophysical Research, 95(B7), 10907-10920. https://doi.org/10.1029/JB095iB07p10907

Garia, S., Pal, A. K., Ravi, K., \& Nair, A. M. (2019). A comprehensive analysis on the relationships between elastic wave velocities and petrophysical properties of sedimentary rocks based on laboratory measurements. Journal of Petroleum Exploration and Production Technology, 9, 1869-1881.

https://doi.org/10.1007/s13202-019-0675-0

Ghazvinian, E., Diederichs, M. S., Labrie, D., \& Martin, C. D. (2015). An investigation on the fabric type dependency of the crack damage thresholds in brittle rocks. Geotechnical and Geological Engineering, 33(6), 1409-1429.

https://doi.org/10.1007/s10706-015-9909-1

Gregg, J. M., \& Sibley, D. F. (1984). Epigenetic dolomitization and the origin of xenotopic dolomite texture. Journal of Sedimentary Research, 54(3), 908-931. https://doi. org/10.1306/212F8535-2B24-11D7-8648000102C1865D

Hajian, J., \& Zahedi, M. (2004). Zanjan geological map report, Iran, scale 1:100000. Geological Survey of Iran.

Hatzor, Y. H., \& Palchik, V. (1998). A microstructure-based failure criterion for Aminadav dolomites. International Journal of Rock Mechanics and Mining Sciences, 35(6), 797-806. https://doi.org/10.1016/S0148-9062(98)00004-7

Hemmati, A., Ghafoori, M., Moomivand, H., \& Lashkaripour, G. R. (2020). The effect of mineralogy and textural characteristics on the strength of crystalline igneous rocks using image-based textural quantification. Engineering Geology, 266, 105467. https://doi.org/10.1016/j.enggeo.2019.105467
Hugman, R. H. H., \& Friedman, M. (1979). Effects of texture and composition on mechanical behavior of experimentally deformed carbonate rocks. American Association of Petroleum Geologists Bulletin, 63(3), 1478-1489. https://doi. org/10.1306/2F9185C7-16CE-11D7-8645000102C1865D

International Society for Rock Mechanics and Rock Engineering. (1978). Suggested method for determining tensile strength of rock material. International Journal of Rock Mechanics and Mining Sciences, 15(3), 99-103.

https://doi.org/10.1016/0148-9062(78)90003-7

International Society for Rock Mechanics and Rock Engineering. (1979a). Suggested methods for determining the uniaxial compressive strength and deformability of rock materials. International Journal of Rock Mechanics and Mining Sciences, 16, 135-140. https://doi.org/10.1016/0148-9062(79)91451-7

International Society for Rock Mechanics and Rock Engineering. (1979b). Suggested method for determining Water Content, Porosity, Density, Absorption and Related Properties and Swelling and Slake-durability Index Properties. International Journal of Rock Mechanics and Mining Sciences, 16(2), 141156. https://doi.org/10.1016/0148-9062(79)91453-0

International Society for Rock Mechanics and Rock Engineering. (1985). Suggested method for determining point load strength. International Journal of Rock Mechanics and Mining Sciences, 22, 51-60. https://doi.org/10.1016/0148-9062(85)92327-7

Lan, H., Martin, C. D., \& Hu, B. (2010). Effect of heterogeneity of brittle rock on micromechanical extensile behavior during compression loading. Journal of Geophysical Research: Solid Earth, 115(B1), B01202.

https://doi.org/10.1029/2009JB006496

Mazzullo, S. J. (1992). Geochemical and neomorphic alteration of dolomite: a review. Carbonates and Evaporites, 7(1), 21-37. https://doi.org/10.1007/BF03175390

Meng, Z., \& Pan, J. (2007). Correlation between petrographic characteristics and failure duration in clastic rocks. Engineering Geology, 89(3-4), 258-265.

https://doi.org/10.1016/j.enggeo.2006.10.010

Nicksiar, M., \& Martin, C. D. (2014). Factors affecting crack initiation in low porosity crystalline rocks. Rock Mechanics and Rock Engineering, 47(4), 1165-1181.

https://doi.org/10.1007/s00603-013-0451-2

Olsson, W. A. (1974). Grain size dependence of yield stress in marble. Journal of Geophysical Research, 79(32), 4859-4862. https://doi.org/10.1029/JB079i032p04859

Palchik, V., \& Hatzor, Y. H. (2000). Correlation between mechanical strength and microstructural parameters of dolomites and limestones in the Judea group, Israel. Israel Journal of Earth Sciences, 49(2), 65-79.

https://doi.org/10.1560/LGVQ-HA9E-P1X7-YRAT

Palchik, V., \& Hatzor, Y. H. (2004). The influence of porosity on tensile and compressive strength of porous chalks. Rock Mechanics and Rock Engineering, 37(4), 331-341. https://doi.org/10.1007/s00603-003-0020-1

Pickett, G. R. (1963). Acoustic character logs and their applications in formation evaluation. Journal of Petroleum Technology, 15(6), 659-667. https://doi.org/10.2118/452-PA

Přikryl, R. (2001). Some microstructural aspects of strength variation in rocks. International Journal of Rock Mechanics and Mining Sciences, 38(5), 671-682.

https://doi.org/10.1016/S1365-1609(01)00031-4

Sibley, D. F., \& Gregg, J. M. (1987). Classification of dolomite rock textures. Journal of Sedimentary Research, 57(6), 967-975. https://doi.org/10.1306/212F8CBA-2B24-11D78648000102C1865D 
Skinner, W. J. (1959). Experiments on the compressive strength of anhydrite. The Engineer.

Sousa, L. M. (2013). The influence of the characteristics of quartz and mineral deterioration on the strength of granitic dimensional stones. Environmental Earth Sciences, 69(4), 13331346. https://doi.org/10.1007/s12665-012-2036-X

Tan, X., Konietzky, H., \& Chen, W. (2016). Numerical simulation of heterogeneous rock using discrete element model based on digital image processing. Rock Mechanics and Rock Engineering, 49(12), 4957-4964. https://doi.org/10.1007/s00603-016-1030-0

Tandon, R. S., \& Gupta, V. (2013). The control of mineral constituents and textural characteristics on the petrophysical \& mechanical (PM) properties of different rocks of the Himalaya. Engineering Geology, 153, 125-143.

https://doi.org/10.1016/j.enggeo.2012.11.005

Ündül, Ö. (2016). Assessment of mineralogical and petrographic factors affecting petro-physical properties, strength and cracking processes of volcanic rocks. Engineering Geology, 210, 10-22. https://doi.org/10.1016/j.enggeo.2016.06.001

Ündül, Ö., Amann, F., Aysal, N., \& Plötze, M. L. (2015). Microtextural effects on crack initiation and crack propagation of andesitic rocks. Engineering Geology, 193, 267-275. https://doi.org/10.1016/j.enggeo.2015.04.024

Wong, R. H., Chau, K. T., \& Wang, P. (1996, July). Microcracking and grain size effect in Yuen Long marbles. International Journal of Rock Mechanics and Mining Sciences \& Geomechanics Abstracts, 33(5), 479-485.

https://doi.org/10.1016/0148-9062(96)00007-1

Zhang, L. (2016). Engineering properties of rocks. ButterworthHeinemann. 